\section{Development of avalanche information system using remote sensing and GIS technology in the Indian Karakoram Himalaya}

\author{
H. S. Gusain*, H. S. Negi, Sudhir Dhamija, \\ V. D. Mishra and Snehmani \\ Snow and Avalanche Study Establishment, Sector 37A, \\ Chandigarh 160 036, India
}

Snow avalanches pose severe threat to lives and property in snow-bound regions of the Western Himalaya. The Karakoram Range in Western Himalaya has the highest mean elevation and is the most glaciated region compared to other ranges. Snowfall in this range is frequent even during summer season. Snow accumulation on mountain slopes results into frequent snow avalanches and several lives have been lost due to snow avalanches in the past. In this communication we discuss about the development of avalanche information system using remote sensing and geographic information system (GIS) technology for the Indian Karakoram Himalaya. High spatial resolution $(0.5 \mathrm{~m})$ PLEIADES satellite images and digital elevation model (DEM) of ASTER GDEM V2 $(30 \mathrm{~m})$ and Cartosat $(10 \mathrm{~m})$ have been used here. Terrain parameters, e.g. slope, aspect, elevation, etc. have been derived using DEM. Sites in avalanche-prone areas have been identified using terrain parameters and snowfall information. Villages in the region, camp locations of borderguarding personnel, pedestrian routes followed by villagers and border-guarding personnel, avalanche sites along pedestrian routes, etc. have been digitized using appropriate GIS vector features, e.g. point, line and polygons. Past avalanche accidents along pedestrian routes, past avalanche occurrences, climatology of the region, etc. have been mapped in GIS environment. Remote sensing and GIS technology proved to be useful for the development of avalanche information system in digital form. The system is being used for avalanche forecasting and mitigation of avalanche hazard in the Indian Karakoram Himalaya.

Keywords: Avalanches, geographic information system, remote sensing, snowfall.

THE Indian Himalaya is broadly classified into Eastern Himalaya in the North East States of India, in central Himalaya in Uttarakhand and Western Himalaya in Jammu and Kashmir (J\&K) and Himachal Pradesh (HP) ${ }^{1}$. The western Himalaya consists of many ranges, e.g. Pir Panjal, Shamshabari, Great Himalaya, Zanskar, Ladakh and Karakoram $^{2}$. These ranges receive snowfall during winter season and most of them are snow-covered. Due to snow accumulation and mountain topography, these ranges are

\footnotetext{
*For correspondence. (e-mail: hs.gusain@sase.drdo.in)
}

vulnerable to snow avalanches. More than 1000 human casualties have been reported in the Western Himalaya because of snow avalanches during the past decades ${ }^{3,4}$. Karakoram Himalaya is the highest, northernmost part of the Western Himalaya. Many villages of Leh district in $\mathrm{J} \& \mathrm{~K}$ are located in Nubra valley, and villagers travel along the pedestrian routes in avalanche-prone areas of Karakoram Himalaya. The Indian territory in Karakoram also shares its boundaries with the neighbouring countries. To safeguard the borders, the Indian Army is also deployed in snow-bound regions of Karakoram. Villagers and border-guarding personnel frequently encounter snow avalanches during winter. Information about avalanche paths in avalanche-prone terrain, avalanche occurrences in the past, avalanche accidents and climatology will provide information about hotspot points vulnerable to such accidents. Such information will contribute in reducing human casualties due to snow avalanches in the region.

Remotely acquired satellite images play a vital role in retrieving information regarding snow-bound regions. Recently, snow cover area variability in different climatic zones of Western Himalaya has been reported using Moderate Resolution Imaging Spectro-radiaometer (MODIS) data for more than a decade ${ }^{5}$. Eckerstorfer et $a l .{ }^{6}$ presented a review on advancements in instrumentation, data analysis and automization techniques while detecting snow avalanches using ground, air- and spaceborne remote sensing data. They highlighted the advantages of remote sensing in snow avalanche study as large coverage of inaccessible terrain without altering the physical property of the snow, possibility of upscaling from point scale to mountain-range scale and all-weather capability in microwave remote sensing. Buhler et al. ${ }^{7}$ presented an automatic mapping technique for avalanche deposits in the Swiss Alps using high-resolution optical remote sensing data, and highlighted the accuracies obtained in detection and mapping. Geographic Information System (GIS) in conjunction with remote sensing and ground-based observation data has been used widely for the development of avalanche information system and simulation of snow avalanches in 3D environment. Rapid Mass MovementS (RAMMS) was developed for natural hazard assessment by simulating snow avalanches on mountain slopes in three-dimensional terrain ${ }^{8}$. RAMMS was successfully used for the analysis of avalanche flow simulation in western Himalaya ${ }^{9}$. Biskupič and Barka ${ }^{10}$ developed a method for outlining the avalanche paths based on computer simulations running in GIS environment in Žiarska valley, located in the Western Tatras, Carpathian Mountain Range, sub-province Western Carpathians, Slovakia. Bourova et al. ${ }^{11}$ reported a comprehensive web-based snow avalanche information system developed in France for managing various avalanche observation data. The three important datasets are (i) an avalanche chronicle, (ii) an avalanche map and (iii) a compilation of hazard and vulnerability data. Delparte et 


\section{RESEARCH COMMUNICATIONS}

$a l .^{12}$ used GIS for runout modelling of snow avalanches in Canada. They have generated snow avalanche runout extent map using statistical alpha-beta model in GIS environment for skiiers, snowboarders, ice climbers and snow mobilers in Rogers Pass area, Glacier National Park, British Columbia, Canada. Omirzhanova et al. ${ }^{13}$ used GIS for predicting the avalanche zones in the foothills of Trans Ili Alatau Mountain Regions of Kazakhstan. In the Indian Himalaya, studies have been conducted to retrieve various snow avalanche parameters using remote sensing data. Gusain et al. ${ }^{2}$ developed an operational algorithm for generation of snow-depth maps using remote sensing and in situ data. The generated snow-depth maps assist in avalanche prediction in the Himalayan ranges. Dewali et al. ${ }^{14}$ generated a global positioning system (GPS)-based real-time avalanche path warning and navigation system. They developed a customized application for Manali-Dhundi area in lower Himalaya in GIS environment for the visualization of terrain maps and navigation while moving in avalancheprone areas. On the basis of digitized avalanche maps, the application updates the traveller on whether his position is inside or outside of the avalanche path. In a few studies, analytical hirarchical process (AHP) has been used for avalanche susceptibility mapping and automatic demarcation of avalanche hazard areas in the Himalayan region $^{15,16}$, Remote sensing and GIS are now being widely used for snow avalanche applications and generation of avalanche information system all over the globe. Avalanche databases have been generated digitally in various countries facing snow avalanche hazard problems, e.g. Canada $^{17}$, Japan ${ }^{18}$, Italy ${ }^{19}$, Switzerland ${ }^{20}$, Norway ${ }^{21}$, etc. In India, Snow and Avalanche Study Establishment (SASE), Chandigarh is the only organization which collects records of avalanche occurrences in various ranges of the Himalaya based on feedbacks from field travellers, villagers and border-guarding personnel. SASE predicts avalanches in the snow-bound regions of J\&K, HP and Uttarakhand Himalaya and various models have been developed for prediction of avalanches in these regions ${ }^{22-25}$. SASE has more than 30 manned meteorological observatories in the Himalaya and avalanche data collected at these locations from various sources are sent to the Research and Development Centre of SASE for compilation, management and further research on the recorded data. SASE has snow avalanche occurrence records in the Indian Himalaya for more than three-decades. Based on past avalanche records and ground survey in the Himalaya, the avalanche atlas in hard-copy format has been generated for many important pedestrian routes and road axes by SASE. Now, with the advancement of technology, the avalanche atlas is being converted into digital format using GIS and remote sensing data. In the present study an avalanche information system has been developed using high-resolution satellite data and GIS technology for the Indian Karakoram Himalaya. The aim of the application is to provide exhaustive information about snow avalanches of the Karakoram Himalaya in 2D and 3D GIS environment. The application is being used by SASE for avalanche hazard mitigation in the Karakoram Himalaya.

Figure 1 shows the study area. The Karakoram Himalaya is the northern most part of the Indian Himalaya and has highest mean elevation compared to other ranges. Generally this range is devoid of vegetation and valleys are mostly glaciated above $4000 \mathrm{~m}$ amsl. The second largest glacier outside the polar region, viz. Siachen glacier is the part of the Karakoram Range. The region is very cold and lowest temperature at an observation station of SASE, viz. Siala (elevation $5500 \mathrm{~m}$ amsl) was recorded as $-40^{\circ} \mathrm{C}$ during winter. Mean of minimum and maximum temperature during the last three decades at this observation station was observed to be $-28.6^{\circ} \mathrm{C}$ and $-15.1^{\circ} \mathrm{C}$ respectively, during the winter months of November to April. Mean snowfall of $1240 \mathrm{~cm} / \mathrm{yr}$ was recorded at the observation station during the past three decades.

Snow avalanches are frequently triggered on mountain slopes in the Karakoram Himalaya after a snowstorm. The feedback of the avalanche occurrences in the region is regularly collected by Mountain Meteorology Centre of SASE at Sasoma village from pedestrians, villagers and border-guarding personnel. Figure 2 shows the total avalanche occurrences reported to SASE during different months in the Karakoram Himalaya during the past three decades. More than 2500 avalanche occurrences have been reported to SASE during different months. February to May are the months with major avalanche activity in the Karakoram Range. More than 200 lives were lost due to avalanches in the Karakoram Himalaya in the past.

PLEIADES-1A satellite sensor data have been used to develop avalanche information system of the Karakoram Himalaya. Ortho-rectified images of PLEIADES at a spatial resolution of $0.5 \mathrm{~m}$ in Panchromatic and $2.0 \mathrm{~m}$ in multispectral were Pan-sharpened at $0.5 \mathrm{~m}$ spatial resolution for better visual elements of the information system. Digital elevation model ASTER GDEM V2 at $30 \mathrm{~m}$ spatial resolution and Cartosat at $10 \mathrm{~m}$ spatial resolution have been used for elevation information and $3 \mathrm{D}$ viewing of the terrain. Roads, pedestrian routes, locations, avalanche occurrence sites, avalanche accident sites, etc. have been digitized using Arc-Map software to generate vector layers in GIS environment. Avalanche polygons have been digitized using terrain parameters and feedback reports on avalanche sites in the field. More than 300 avalanche sites have been marked in the study area along various routes followed by villagers, border-guarding personnel and field travellers.

The avalanche information system was developed on a customized QGIS (previously known as Quantum GIS) platform, which is a freely available open-source desktop GIS. It functions as a GIS software and supports viewing, 


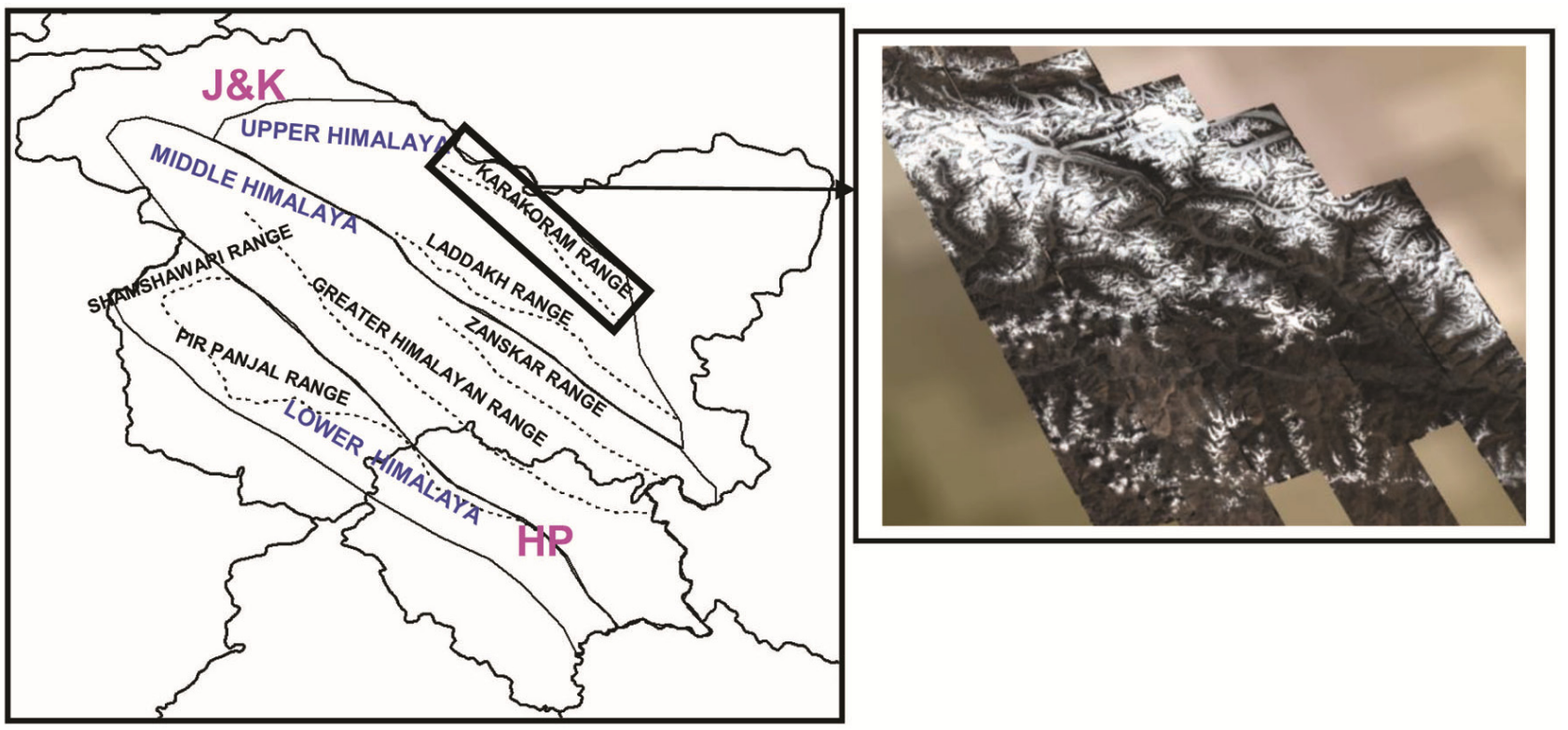

Figure 1. Indian Himalayan mountain ranges and satellite image of Karakoram Himalaya.

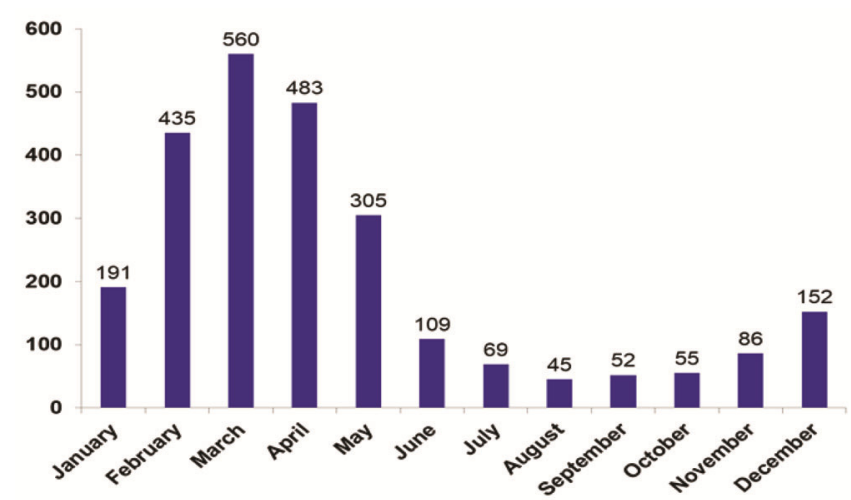

Figure 2. Avalanche occurrences in the Karakoram Range during the past.

editing, managing and analysis of geospatial data, i.e. raster and vector data formats. The software code is written in $\mathrm{C}++$. The application has $2 \mathrm{D}$ and $3 \mathrm{D}$ viewing features and the key features are seamless and interactive viewing of geospatial data, dynamic viewing of satellite maps, opening vector and raster data formats, dynamic viewing of vector data with raster data, vector data editing, multiple theme selection (checking and unchecking of vector and raster data), feature identification tool, layer controller to on/off a vector layers, map annotation, editing of map annotation, tools for pan, zoom-in, zoom-out and overall view, measurement tool for measuring distance and calculating polygon area, tool for rotating view of display with respect to north, 3D navigation with zoom-in and zoom-out option, display of terrain information (latitude, longitude, elevation) corresponding to the curser point and display of attribute data with vector selection.
The application has 2D and 3D geographic user interface (GUI) which is divided into five areas: (i) Menu Bar, (ii) Tool Bar, (iii) Layer Legend, (iv) Map Canvas and (v) Status Bar. Figure 3 shows the GUI of the application.

The menu bar has features of selection of file, navigation control, video options and utility tools. The user can select raster or vector file to open from the file menu. Based on the selection, appropriate data are loaded in the corresponding layer legend. The user can select multiple files one by one, and checkin and checkout the files. Using navigation control the selected map can be moved and rotated up, down, left and right.

The user can directly interact with vector and raster files utilizing different icons on the tool bar. He/she can open vector or raster data file, pan and rotate the maps in 2D and 3D up/down/left/right. There are icons for line of sight and feature identification. The user can display the attribute data of the vector layers through display icon on the tool bar.

The layer legend area lists all the selected raster and vector layers. The check box in each legend entry can be used to show or hide the layer in map canvas.

Selected raster and vector data are displayed in the map canvas window. The map canvas can be panned, zoomedin and zoomed-out. Various other operations can be performed on the map in the map canvas. The map canvas and legend are tightly bound to each other. The maps in the map canvas reflect changes which are made in the layer legend.

The status bar holds labels displaying latitude, longitude and altitude values. These are the values corresponding to the curser point on the map in map canvas. 


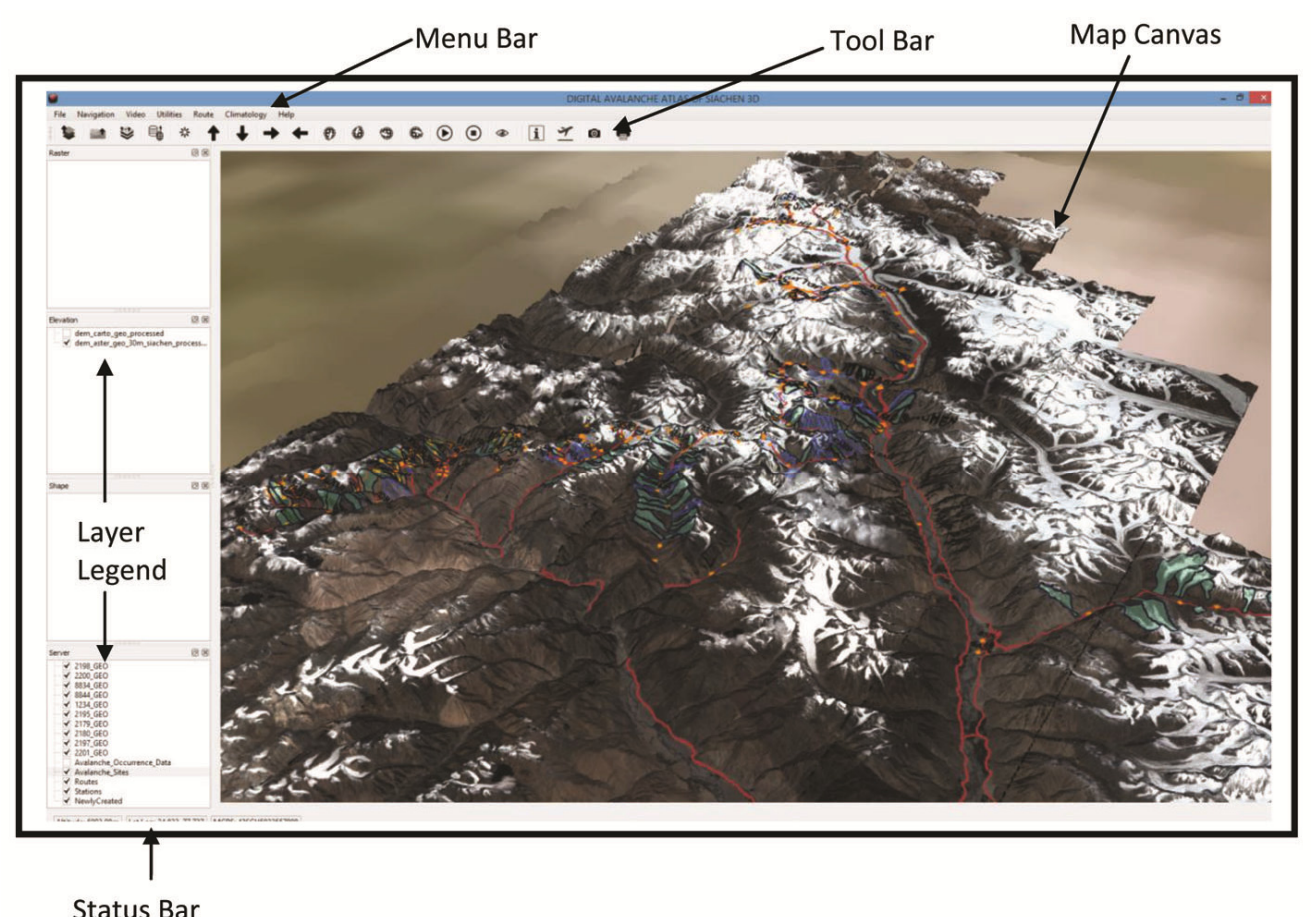

Figure 3. Geographic User Interface of the application showing menu bar, tool bar, layer legend, map canvas and status bar.

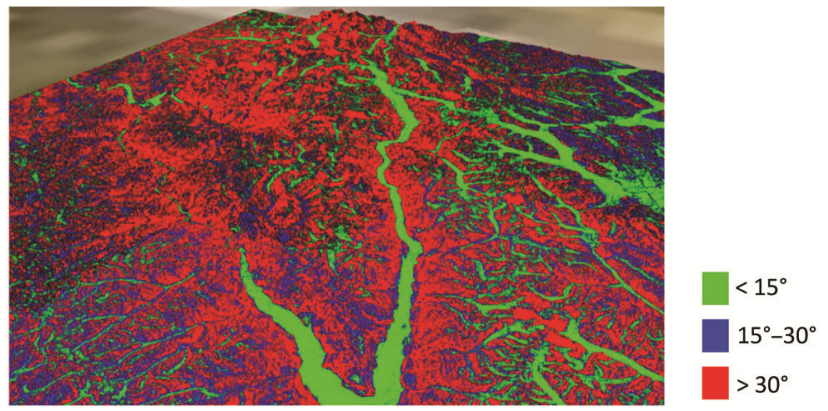

Figure 4. Slope image (categories: $<15^{\circ}, 15^{\circ}-30^{\circ}$ and $>30^{\circ}$ ) of the study area.

Vector layers of routes, stations, avalanche sites, zones of avalanche sites, past avalanche occurrences, past avalanche accidents, etc. have been generated using appropriate GIS elements. Stations, routes and avalanche sites have been digitized using point, line and polygon respectively. Avalanche sites have been identified using terrain features and past avalanche records. First, those points on the terrain are mapped where avalanches have been reported in the past. Once an avalanche has been reported at a location in the past, the path of the avalanche is identified using flow channels developed on digital elevation model of the terrain. The terrain having $>30^{\circ}$ slope in the avalanche is digitized as formation zone, terrain with slope $>15^{\circ}$ and $<30^{\circ}$ is digitized as middle zone, and avalanche path with slope $<15^{\circ}$ is digitized as run-out zone ${ }^{26}$. More than 300 avalanche sites have been mapped in the
Karakoram Himalaya along the routes/pedestrian tracks, where movement is affected by avalanches. Figure 4 shows the slope image of the study area. Figure 5 shows the formation, middle and run-out zones of an avalanche site in the Karakoram Himalaya based on slope image.

All avalanche occurrences and avalanche accidents in the Karakoram Himalaya reported to SASE have been digitized. Totally more than 2500 avalanche occurrences have been digitized as point data. Each avalanche incident mapped as a point vector carries an attribute file having details of the incident as follows: date of avalanche occurrence, time of occurrence, latitude and longitude, road axes, number of persons caught in the avalanche, number of persons who died in the avalanche, number of persons who survived, etc. Figure 6 shows details of an attribute table related to an avalanche accident. The table will open as one presses the information icon given in the tool bar after selection of the particular vector point related to the avalanche incident from all the digitized incidents. These vector layers can be updated as the new incidents are reported to SASE.

SASE has 10 ground observatory locations in different parts of the Karakoram Himalaya, viz. north, central, south, west, etc. These observatories collect snow-meteorological data at $0830 \mathrm{~h}$ and $1730 \mathrm{~h}$ local time, according to the World Meteorological Organization guidelines. Climatological graphs of the parameters maximum temperature, minimum temperature, snowfall and wind speeds of past three decades have been included in the avalanche information system and one can view them by 


\section{RESEARCH COMMUNICATIONS}

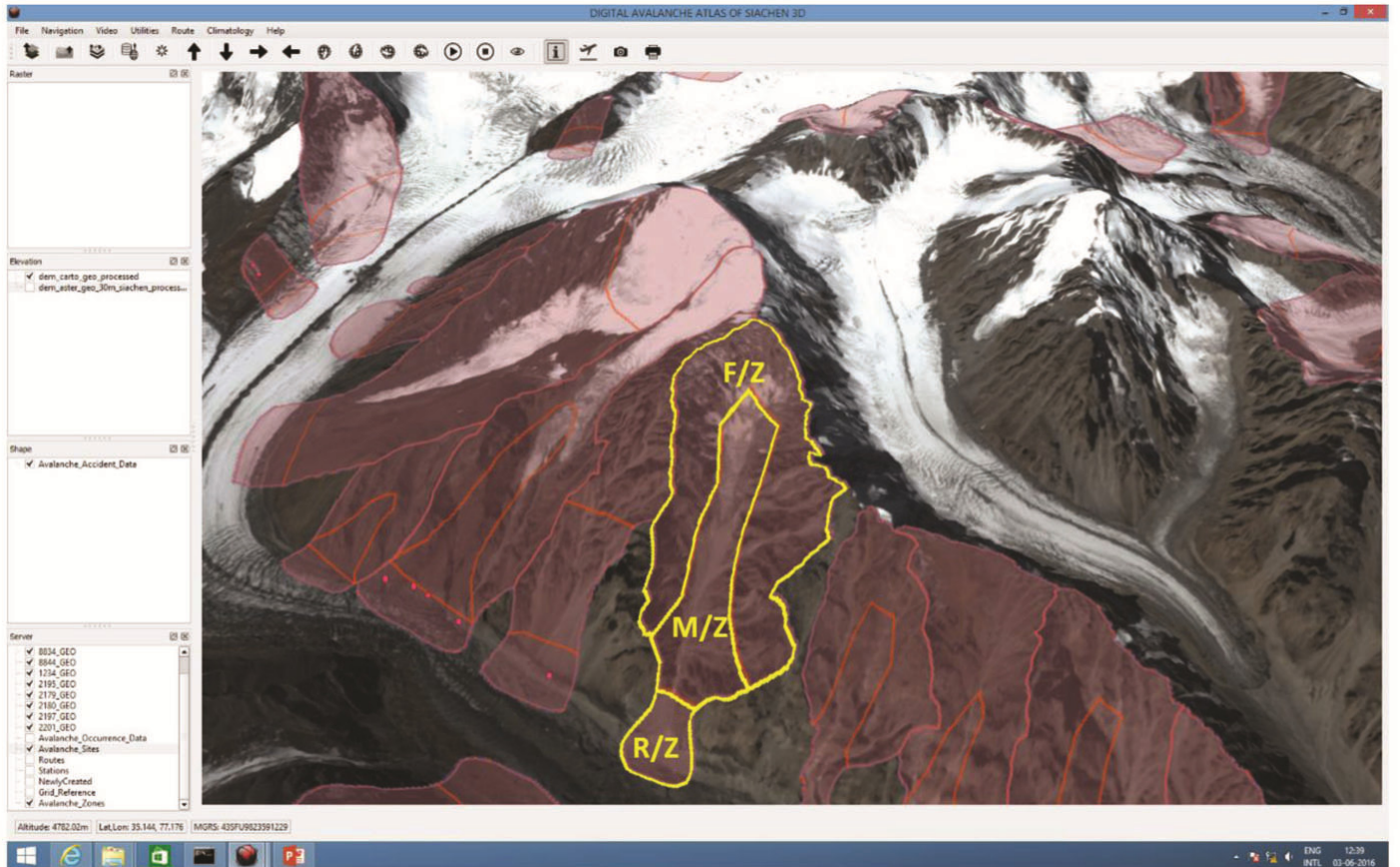

Figure 5. Formation zone, middle zone and run-out zone.

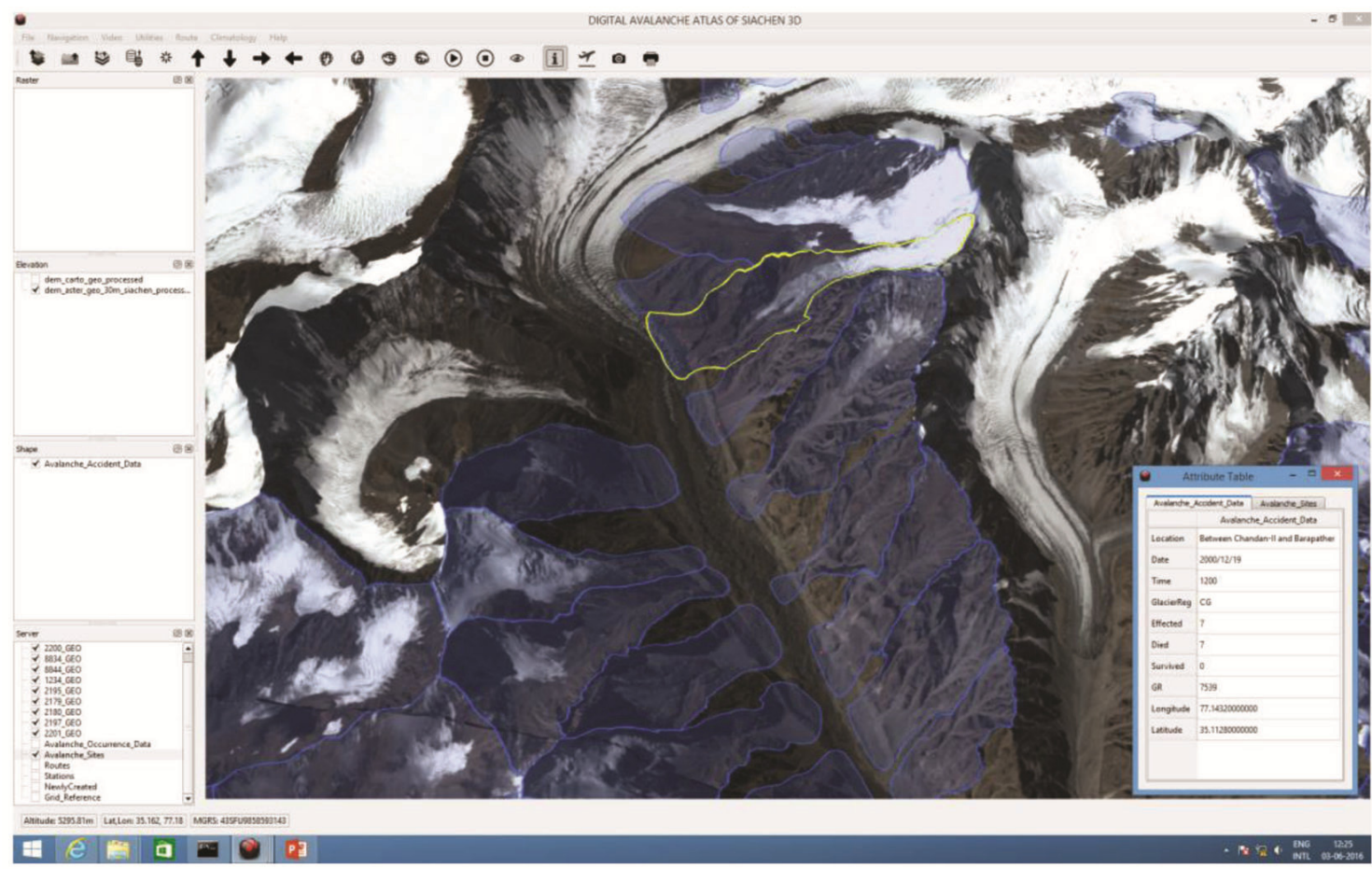

Figure 6. View of attribute table related to one of the avalanche accidents in the study region.

selecting the climatology icon in the menu bar. A list of observation locations will appear and after selection of one observation location climatological graphs will appear on the screen of the selected observatory.

In summary, a novel application has been developed for snow avalanche information in the Indian Himalaya, although it covers only the Karakoram Himalaya. High spatial resolution PLEIADES images provide detailed surface features of the terrain at $0.5 \mathrm{~m}$ resolution. Opensource QGIS is customized for the development of the application using the code in $\mathrm{C}++$. Cartosat DEM of $10 \mathrm{~m}$ and ASTER GDEM V2 of $30 \mathrm{~m}$ have been used in the 


\section{RESEARCH COMMUNICATIONS}

application for 3D-viewing of the terrain. Vector layers of the avalanche sites, avalanche zones, pedestrian routes, camp/village locations, locations of past avalanche occurrences, locations of past avalanche accidents, etc. have been created in GIS environment. Each vector layer has an attribute table with detailed information about the vector. The attribute table can be viewed along with the vector layer on the desktop. The application has $2 \mathrm{D}$ and 3D GUI, and the terrain can be navigated using zoom-in, zoom-out and rotation features. The application has detailed snow avalanche information of the past three decades for the Karakoram Himalaya, and also includes climatology of the region. Remote sensing and GIS technology proved to be useful for the development of avalanche information system in digital form. Presently, the application is being used in the mitigation of avalanche hazard and forecasting of snow avalanches in the Karakoram Himalaya by SASE in the country.

1. Sharma, S. S. and Ganju, A., Complexities of avalanche forecasting in Western Himalaya: an overview. Cold Reg. Sci. Technol., 2000, 31, 95-102.

2. Gusain, H. S., Mishra, V. D., Arora, M. K., Shailesh, M. and Singh, D. K., Operational algorithm for generation of snow depth maps from discrete data in Indian Western Himalaya. Cold Reg. Sci. Technol., 2016, 126, 22-29.

3. McClung, D. M., Avalanche character and fatalities in the high mountains of Asia. Ann. Glaciol., 2016, 57(71), 114-118.

4. Ganju, A., Thakur, N. K. and Rana, V., Characteristics of avalanche accidents in western Himalayan region, India. In Proceedings of the International Snow Science Workshop, Penticton, B.C., Canada, 29 September-4 October 2002, pp. 200-207.

5. Singh, D. K., Gusain, H. S., Mishra, V. D. and Gupta, N., Snow cover variability in North-West Himalaya during last decade. Arab. J. Geosci., 2018, 11, 579.

6. Eckerstorfer, M., Bühler, Y., Frauenfelder, R. and Malnes, E., Remote sensing of snow avalanches: recent advances, potential and limitations. Cold Reg. Sci. Technol., 2016, 121, 126-140.

7. Buhler, Y., Huni, A., Christen, M., Meister, R. and Kellenberger, T., Automated detection and mapping of avalanche deposits using airborne optical remote sensing data. Cold Reg. Sci. Technol., 2009, 57, 99-106.

8. Christen, M., Kowalski, J. and Bartelt, P., RAMMS: Numerical simulation of dense snow avalanches in three-dimensional terrain. Cold Reg. Sci. Technol., 2010, 63, 1-14.

9. Gusain, H. S., Mishra, V. D. and Singh, D. K., Study of a snow avalanche accident along Chowkibal-Tangdhar road in Kupwara district, Jammu and Kashmir, India. Curr. Sci., 2018, 115(5), 969972.

10. Biskupič, M. and Barka, I., Spatial modelling of snow avalanche run-outs using GIS. Symposium GIS, Ostrava, Czech Republic, 24-27 January 2010.

11. Bourova, E., Maldonado, E., Leroy, J.-B., Alouani, R., Eckert, N., Bonnefoy-Demongeot, M. and Deschatres, M., A new web-based system to improve the monitoring of snow avalanche hazard in France. Nat. Hazards Earth Syst. Sci., 2016, 16, 1205-1216.

12. Delparte, D., Jamieson, B. and Waters, N., Statistical runout modeling of snow avalanches using GIS in Glacier National Park, Canada. Cold Reg. Sci. Technol., 2008, 54, 183-192.

13. Omirzhanova, Zh. T., Urazaliev, A. S. and Aimenov, A. T., GIS for predicting the avalanche zones in the mountain regions of
Kazakhstan. Int. Arch. Photogramm. Remote Sensing Spat. Inf. Sci., 2015, XL-2/W4, 39-44.

14. Dewali, S. K., Joshi, J. C., Ganju, A. and Snehmani, A GPS-based real-time avalanche path warning and navigation system. Geomat. Nat. Hazards Risk, 2014, 5(1), 56-80.

15. Kumar, S., Srivastava, P. K. and Snehmani, GIS-based MCDAAHP modelling for avalanche susceptibility mapping of Nubra Valley region, Indian Himalaya. Geocarto Int., 2017, 32(11), 1254-1267.

16. Singh, D. K., Mishra, V. D., Gusain, H. S., Gupta, N. and Singh, A. K., Geo-spatial modeling for automated demarcation of snow avalanche hazard areas using Landsat- 8 satellite images and in situ data. J. Indian Soc. Remote Sensing, 2019; doi.org/10.1007/ s12524-018-00936-w

17. Haegeli, P., Obad, J., Harrison, B., Murray, B., Engblom, J. and Neufeld, J., InfoexTM 3.0-advancing the data analysis capabilities of Canada's diverse avalanche community. In Proceedings of the International Snow Science Workshop, Banff, Alberta, Canada, 29 September-3 October 2014, pp. 910-917.

18. Akiyama, K. and Ikeda, S., Features of avalanches based on aerial photograph interpretation in Japan. In Proceedings of the International Snow Science Workshop, Grenoble, France, 7-11 October 2013, pp. 707-714.

19. Debernardi, A. and Segor, V., The avalanche cadaster of the Valle d'Aosta Region (NW Italian Alps: the new born web portal (http://catastovalanghe.partout.it/). In Proceedings of the International Snow Science Workshop, Grenoble, France, 7-11 October 2013, pp. 446-450.

20. Ruesch, M., Egloff, A., Gerber, M., Weiss, G. and Winkler, K., The software behind the interactive display of the Swiss avalanche bulletin. In Proceedings of the International Snow Science Workshop, Grenoble, France, 7-11 October 2013, pp. 406-412.

21. Jaedicke, C., Syre, E. and Sverdrup-Thygeson, K., GIS-aided avalanche warning in Norway. Comput. Geosci., 2014, 66, 31-39.

22. Ganju, A. and Dimri, A. P., Prevention and mitigation of avalanche disasters in Western Himalayan Region. Nat. Hazards, 2004, 31, 357-371.

23. Singh, A., Srinivasan, K. and Ganju, A., Avalanche forecast using numerical weather prediction in Indian Himalaya. Cold Reg. Sci. Technol., 2005, 43, 83-92

24. Joshi, J. C. and Ganju, A., Avalanche warning on ChowkibalTangdhar axis (J\&K): a hybrid approach. Curr. Sci., 2006, 91(11), 1558

25. Joshi, J. C. and Srivastava, S., A hidden Markov model for avalanche forecasting on Chowkibal-Tangdhar road axis in Indian Himalayas. J. Earth Syst. Sci., 2014, 123(8), 1771-1779.

26. McClung, D. and Schaerer, P., The Avalanche Handbook, The Mountaineers Books, Seattle, WA, USA, 1993.

ACKNOWLEDGEMENTS. We thank the Director, SASE, Chandigarh for constant encouragement, and the scientists/technical officers/ staff of SASE for collection and compilation of snow avalanche and climatology data of Karakoram Himalaya. We also thank NASA, USA for providing ASTER DEM (https://asterweb.jpl.nasa.gov).

Received 28 July 2018; revised accepted 8 May 2019

doi: $10.18520 / \mathrm{cs} / \mathrm{v} 117 / \mathrm{i} 1 / 104-109$ 